\title{
ANALYSIS OF THERMAL COMFORT IN A SINGLE- FAMILY HOUSE IN POLAND
}

\author{
Natalia KRAWCZYK ${ }^{1, *}$, Sylwia SURMAŃSKA ${ }^{1}$ \\ ${ }^{1}$ Faculty of Environmental, Geomatic and Energy Engineering, Kielce University of Technology, \\ 25 - 314 Kielce, Poland. \\ corresponding author: nkrawczyk@tu.kielce.pl.
}

\section{Abstract}

The article presents test research on thermal sensations, thermal preferences, as well as general thermal sensations in a single-family building. Graphs were drawn to determine the frequency of answers chosen by the respondents and the relationship between temperature and thermal sensations, as well as the influence of relative humidity on thermal sensations. A comparison was also made between the average thermal sensation vote and the PMV index, which determines the 'predicted mean vote' - estimated by the Fanger model. The aim of the study was to compare the actual feelings of the respondents with standard guidelines. As a result of this analysis it was found that the thermal sensations of the respondents do not comply with the adonted model included in the standard.
\end{abstract}

\section{Keywords:}

Thermal comfort; Predicted mean vote; Fanger's model;

Thermal preference;

Thermal sensation.

\section{Introduction}

Nowadays, more and more people are living in rooms with artificially created climate. This causes increased interest in the conditions in a given room. Therefore, the aim is to ensure adequate thermal comfort by using appropriate air conditioning and heating devices. Thermal comfort is a state of human satisfaction with the conditions prevailing in the room in which he or she is staying at a given moment. Inappropriate conditions in the room can even lead to illness, and as a result, the best possible parameters are sought for the feeling of comfort [1]. The main parameters affecting the determination of thermal comfort are air temperature, air velocity, relative humidity, average radiation temperature and physical activity.

Fanger determined the Predicted Mean Vote (PMV) index to determine the average value of the vote on the seven-point rating scale [2]. It determined that people dissatisfied with the conditions in the room, they are currently in, include those who assess the thermal environment as hot, warm, cool, cold on the seven-point scale. The model developed by Fanger [1] on the basis of the applicable standards: ISO 7730 [2], ASHRAE 55 [3] and PN-EN 16798 [4] is used to predict the thermal sensations.

Kiil [5] conducted a study on thermal comfort in office buildings in Tallinn, Estonia, and concluded that the thermal sensations voted by occupants differ significantly from the calculations based on the Fanger model. Majewski et al. $[6,7]$ conducted research in an intelligent building and observed differences between the projected and actual values of thermal comfort, so the best solution is to modify the PMV index. Siew et al. [8] came to a similar conclusion. Modification of the index will provide reliable guidelines for designers. Ricciardi and Buratti [9] proposed to use a thirteen-stage comfort scale instead of the seven-stage ISO 7730 [2], but no significant change in the results was observed. Jazizadeh et al. [10] analyzed thermal comfort in office buildings and indicated that the most important factor that affects thermal comfort is air temperature. Ji et al. [11] showed that the human body is more sensitive to cold temperatures than to warm ones. Based on the papers [12, 13], it can be concluded that air temperature and humidity have the greatest influence on the thermal sensations. Thus, changes in temperature affect the impression of thermal comfort.

The article analyses thermal sensations in a single-family, two-storey building in Poland. On the basis of the literature review it should be noted that the Fanger model does not reflect the results of 
the respondents. The purpose of this study is also to compare the real feelings of the respondents with standard guidelines.

\section{Material and method}

The research on thermal comfort consisted in registering selected microclimate parameters, i.e. air temperature and relative humidity in a single-family, two-storey house with 12 rooms, located in Gnojno commune, Swietokrzyskie province in Poland. The building is made of $24 \mathrm{~cm}$ thick cellular concrete. It is insulated with $10 \mathrm{~cm}$ thick polystyrene foam. All series of measurements were carried out in one room, i.e. in the living room (Fig. 1 and 2).

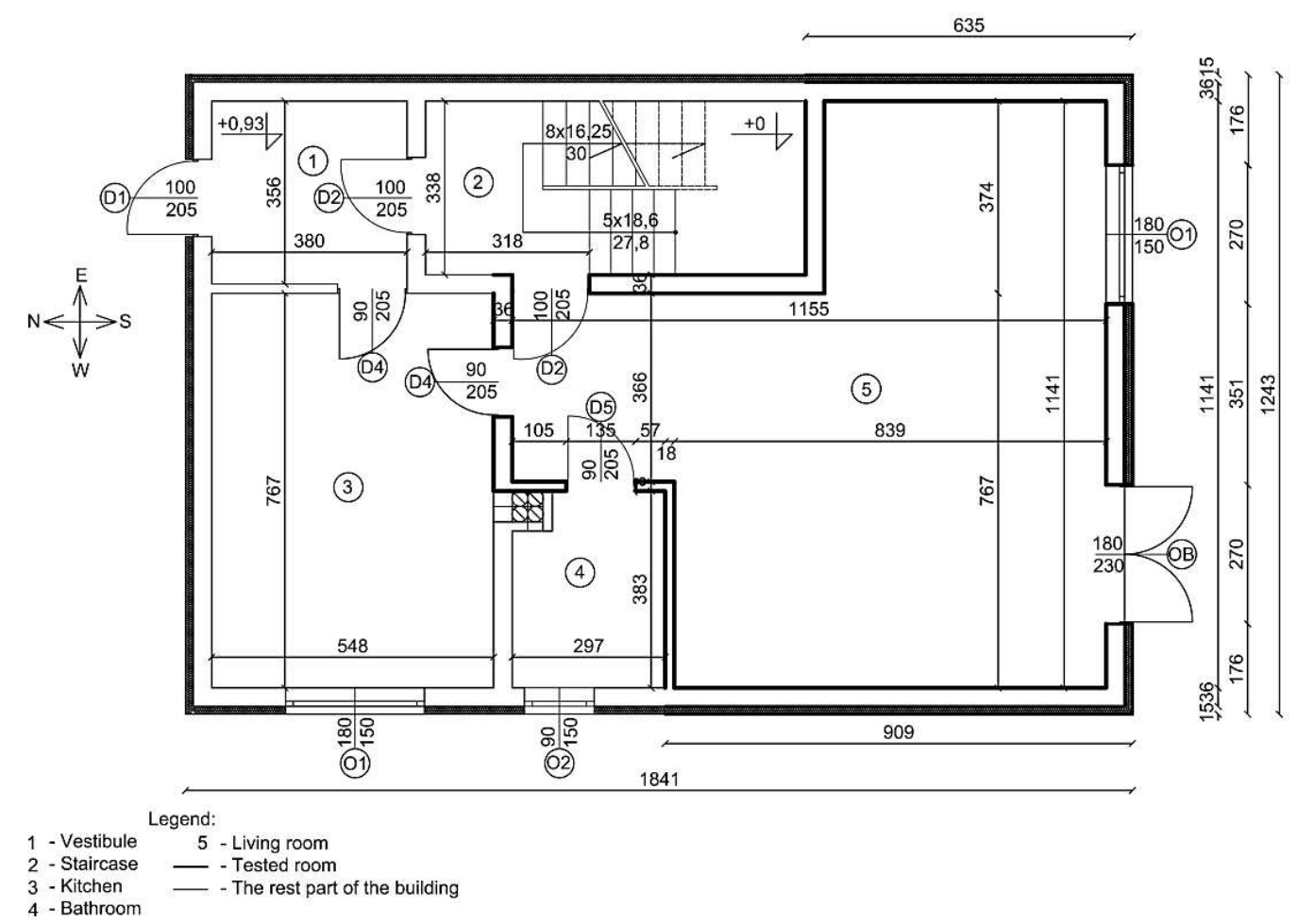

Fig. 1: Schematic of the room where the tests were carried out together with its dimensions.

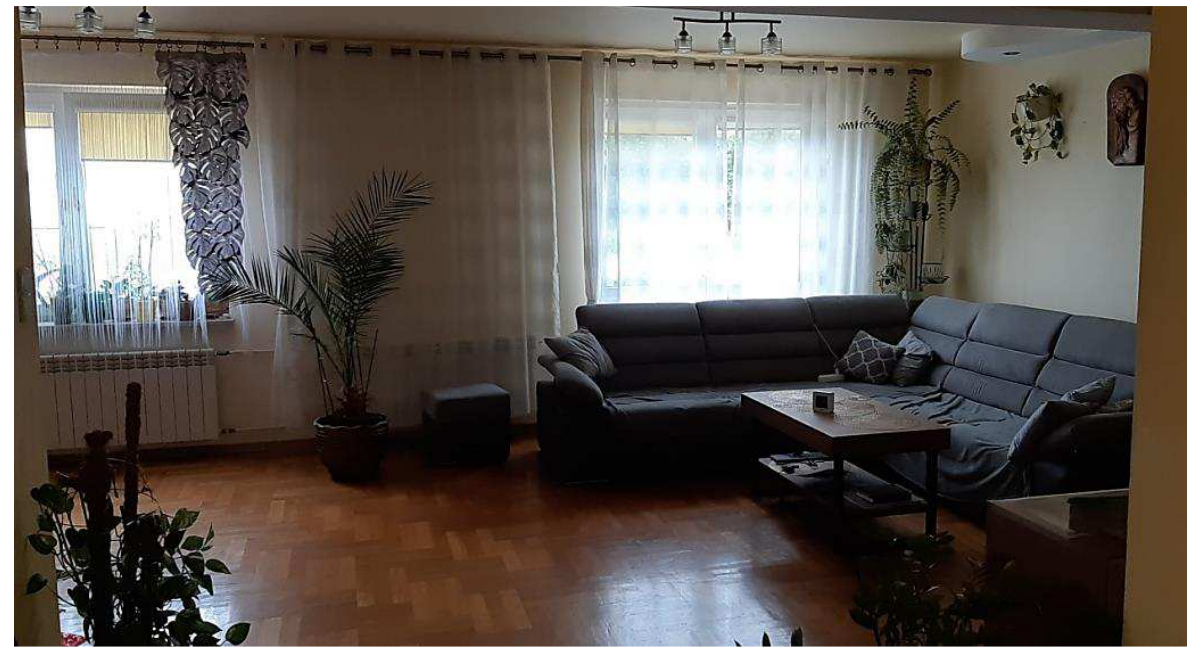

Fig. 2: Photograph of the room where the tests were taken.

During each examination there were 8 people in the room. Determination of temperature and humidity was possible after 15 minutes, because this time allowed to stabilise the measured parameters. During the stabilisation process all household members were given questionnaires concerning the feeling of thermal sensations in the room. The tests were conducted over a period of 2 weeks. At that time, the outside temperature ranged from 12 to $24^{\circ} \mathrm{C}$. 


\section{Results and discussion}

The study was attended by 8 people, among them 4 women and 4 men. Volunteers completed 112 questionnaires in total. The graph below shows the frequency of answers given with regard to thermal sensations vote felt by women and men in the room (Fig. 3).

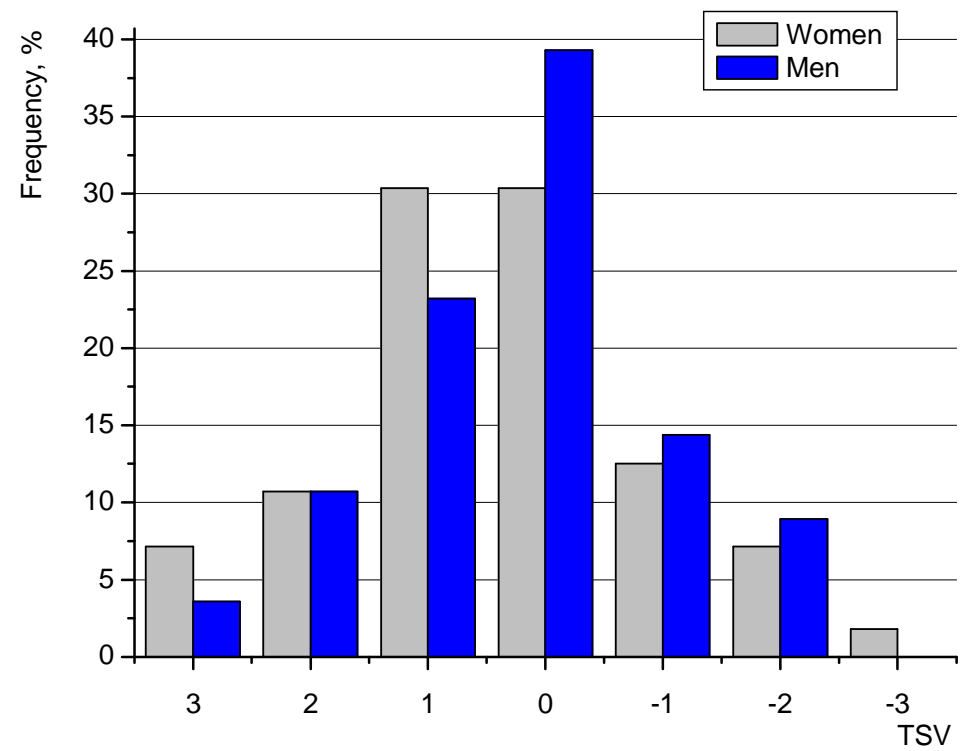

Fig. 3: Frequency of answers given by respondents regarding Thermal Sensations Vote (TSV): ' 3 ' Too hot, '2' - Too warm, ' 1 ' - Pleasantly warm, '0' - Comfortable, '-1' - Pleasantly cool, '-2' - Too cool, '-3' - Too cold.

The conducted research (for women) shows that the answer, 'too hot' was marked 4 times ( $7.14 \%$ of the answers by female respondents). The answer 'too warm' was chosen 6 times (10.71 $\%)$. 'Pleasantly warm' was selected 17 times. In this case, the frequency was $30.36 \%$. The same percentage was obtained by answer 'comfortable'. The 'pleasantly coo' option was repeated 7 times, or $12.50 \%$ of the total. The frequency for 'too cool' and 'too cold' answers was $7.14 \%$ and $1.79 \%$ respectively. To sum up, the obtained questionnaires show that the women most often felt comfortable or pleasantly warm in a room. The frequency of both answers is $60.72 \%$.

In the case of men, the answer 'too hot' was chosen only twice, which represents $3.57 \%$ of the results obtained by male person. The 'too warm' option was selected 6 times or $10.71 \%$ of the total. The answer 'pleasantly warm' was repeated 13 times, which corresponds to $23.21 \%$, while the answer 'comfortable' was marked 22 times. In this case, the frequency was $39.29 \%$. The 'pleasantly cool' and 'too cool' options are $14.29 \%$ and $8.93 \%$. Thus, according to the conducted surveys, men felt comfortable in the room and did not feel cold.

Comparing the results of the conducted research, it can be concluded that males more often indicated the answers 'comfortable' and 'pleasantly cool'. The difference in the frequency of marked answers is $8.93 \%$ and $1.79 \%$, respectively. However, in the case of the answer 'pleasantly warm', women chose this option more often. The difference between women and men is $7.14 \%$. Summing up, the differences between the thermal sensation vote in men and women are small. However, men felt better in the room than women.

Taking into account all the answers given by women and men, it can be concluded that the respondents did not feel comfortable in the room, i.e. there was no thermal comfort in the place where they were staying, because the percentage of the option $-3,-2,+2,+3$ (Fig.3) was greater than $10 \%$ and amounted to $25 \%$. This means that $25 \%$ of people were dissatisfied with the conditions in the room. The study by Majewski et al. [13] additionally confirms that statistically men feel more comfortable than women. The graph below (Fig. 4) shows the frequency of answers given with regard to temperatures experienced by women and men in the room. 


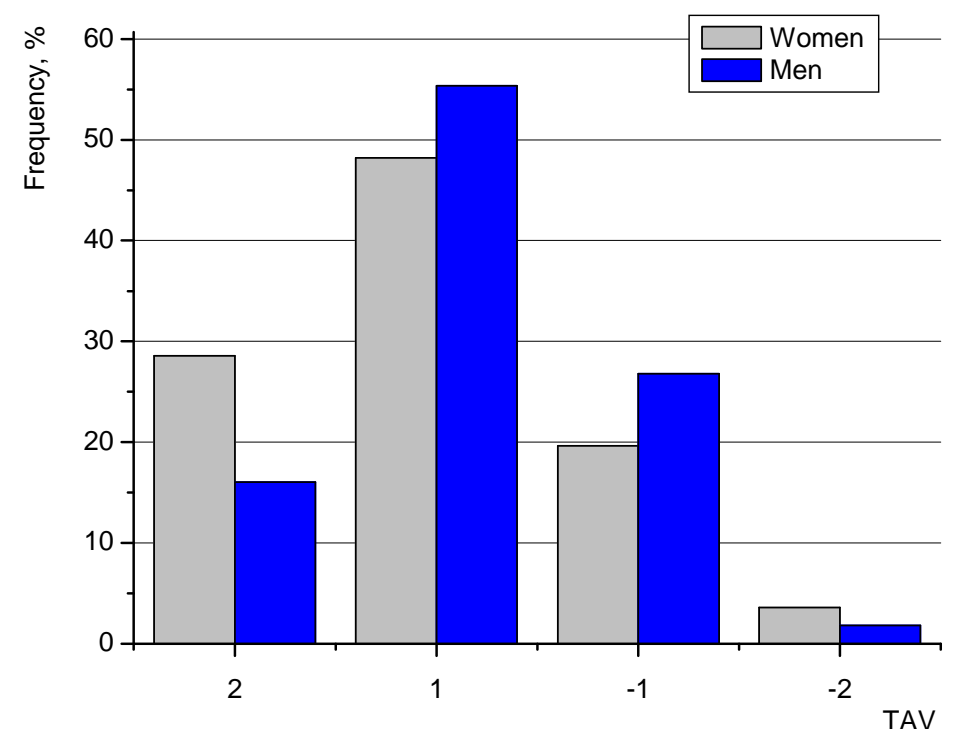

Fig. 4: Frequency of the answers given regarding Thermal Acceptability Vote (TAV) experienced by the respondents: ' 2 ' - Comfortable, '1' - Acceptable, '-1' - Unpleasant, '-2' - Definitely unpleasant.

The conducted research in the case of women shows that the answer 'comfortable' was marked 16 times, which is $28.57 \%$ of all answers given by women. The 'acceptable' option was repeated 27 times (48.21\%). The answers 'unpleasant' and 'definitely unpleasant' constitute $19.64 \%$ and $3.57 \%$, respectively. In conclusion, most of the women in the room were satisfied with the thermal conditions, only $23.21 \%$ did not correspond to the existing conditions.

The research carried out on men shows that 9 times the answer about the temperature in the room was given that it is 'comfortable'. The frequency of answers is $16.07 \%$. In the case of the answers 'acceptable' it was given 31 times (55.36 \% of the marked male answers). The choice 'unpleasant' option was $26.79 \%$. The least frequently chosen answer was 'definitely unpleasant'; it represents only $1.79 \%$ of all answers.

The answers given by men and women show that women are more satisfied with room conditions than men. The difference between the answers given is $5.36 \%$. In general, the respondents were satisfied with the prevailing conditions, only $25.89 \%$ of the respondents were not satisfied with the temperature of the environment in which they were located. The frequency of answers given by women and men regarding thermal acceptability vote in the room is presented in the diagram below (Fig. 5).

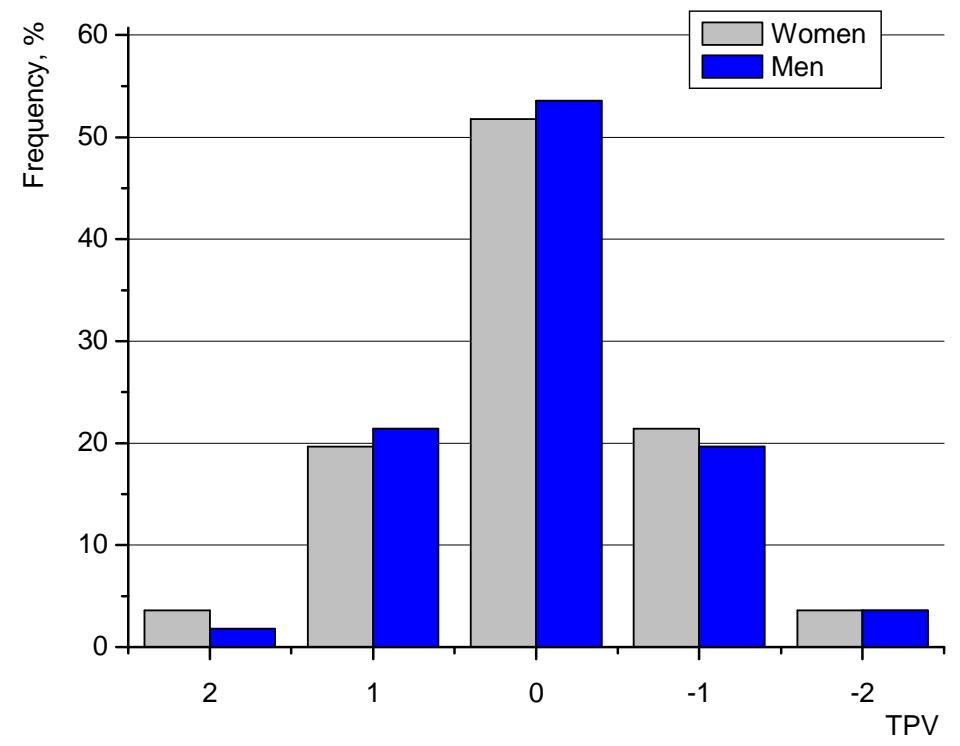

Fig. 5: Frequency of answers given by the respondents regarding Thermal Preferences Vote (TPV):

'2' -Definitely warmer, ' 1 ' - Warmer, '0' - No change, '-1' - Cooler, '-2' - Definitely cooler. 
The research shows that women answered twice, 'definitely warmer' in terms of thermal preferences, which is $3.57 \%$. In the case of the 'warmer' option, the frequency of this answer is $19.64 \%$, that is, out of 56 questionnaires 11 were assessed in this way. The most frequently given answer was 'no change' option. It constitutes as much as $51.79 \%$ of all questionnaires filled in by women. The answer 'definitely cooler' occurs as many times as the option 'definitely warmer'. The above graph shows that women assessed their thermal preferences vote as neutral.

In the case of men, the answer 'definitely warmer' was given only once, i.e. the frequency of this option was $1.79 \%$. Male respondents answered 'warmer' 12 times, i.e. $21.43 \%$, while the 'no change' option was selected 30 times, i.e. the frequency was $53.57 \%$. The 'cooler' and 'definitely cooler' options appeared 11 and 2 times, which is $19.64 \%$ and $3.57 \%$, respectively.

From the answers given by women and men, it can be concluded that their thermal preferences votes are very close to each other. The difference between the answer 'no change' is small, amounts to $1.79 \%$, and was chosen most often. The same is true for the remaining options. The rarest answers were 'definitely warmer' and 'definitely cooler' options. Therefore, it can be stated that the respondents felt good in the room. Only $24.1 \%$ of people thought that the room was in bad conditions. The graph below shows the frequency of the given responses to general sensation vote: by women and men in the room (Fig. 6).

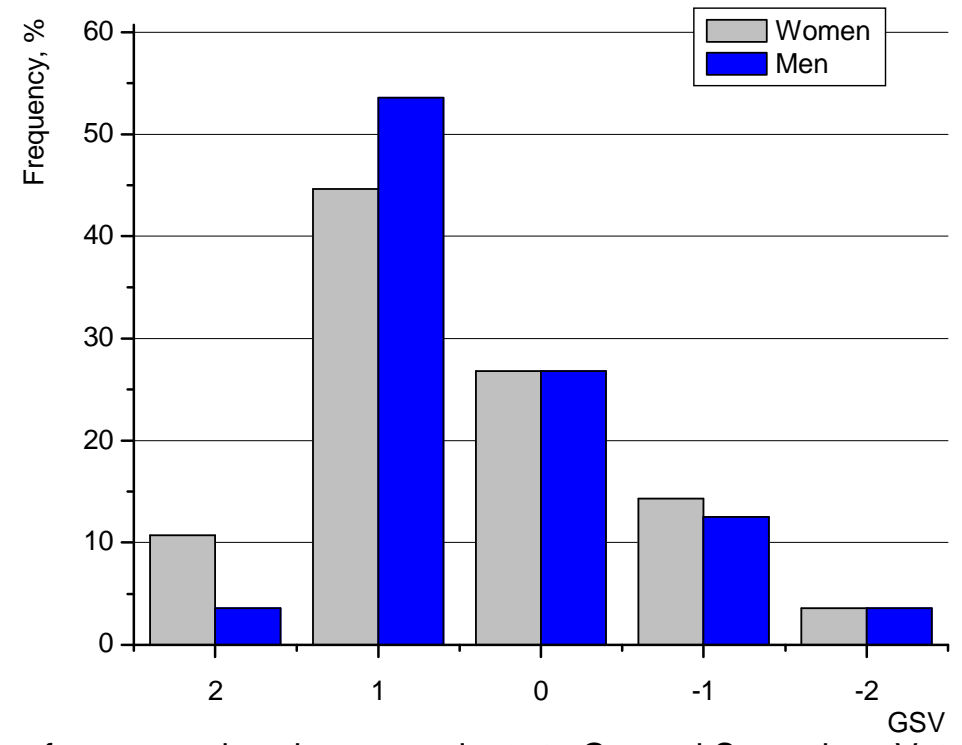

Fig. 6: Frequency of answers given by respondents to General Sensations Vote (GSV): '2' - Very good, '1' - Good, '0' - Indifferently, '-1' - Bad, '-2' - Very bad.

Research has shown that women have chosen the 'very good' option 6 times. The frequency in this case is $10.71 \%$ of all answers given by the female gender. The answer 'good' is $44.64 \%$, which corresponds to 25 answers out of 56. The second highest number of answers chosen is the 'indifferent' option. It was repeated 15 times, i.e. its frequency is $26.79 \%$. The 'bad' and 'very bad' options are $14.29 \%$ and $3.57 \%$ of all answers marked by women. In summary, in most cases women felt good in the room.

The research conducted on men showed that the frequency of selected answers 'very good' and 'very bad' was the same and was $3.57 \%$ each. The most frequent answer was 'good'. It constitutes as much as $53.57 \%$ of all questionnaires filled in by men. The 'indifferently' option was repeated 15 times or $26.79 \%$ of the total. The answer 'bad' was chosen by the respondents 7 times. The frequency of this answer was $12.50 \%$.

The analysis of the above graphs showed that men were more likely to mark the 'good' answer in relation to women. The difference was $8.93 \%$. However, in the case of the answers 'very good', women were more likely to express such opinions. The remaining feelings are very close to each other. In general, the respondents felt good in their environment, only $16.96 \%$ of people expressed negative opinions on the general sensations vote.

Another part of the study focused on the search for possible explanations to the obtained results. The relationship between temperature and thermal sensations vote (TSV) felt by the respondents is presented in the diagram below (Fig. 7). 


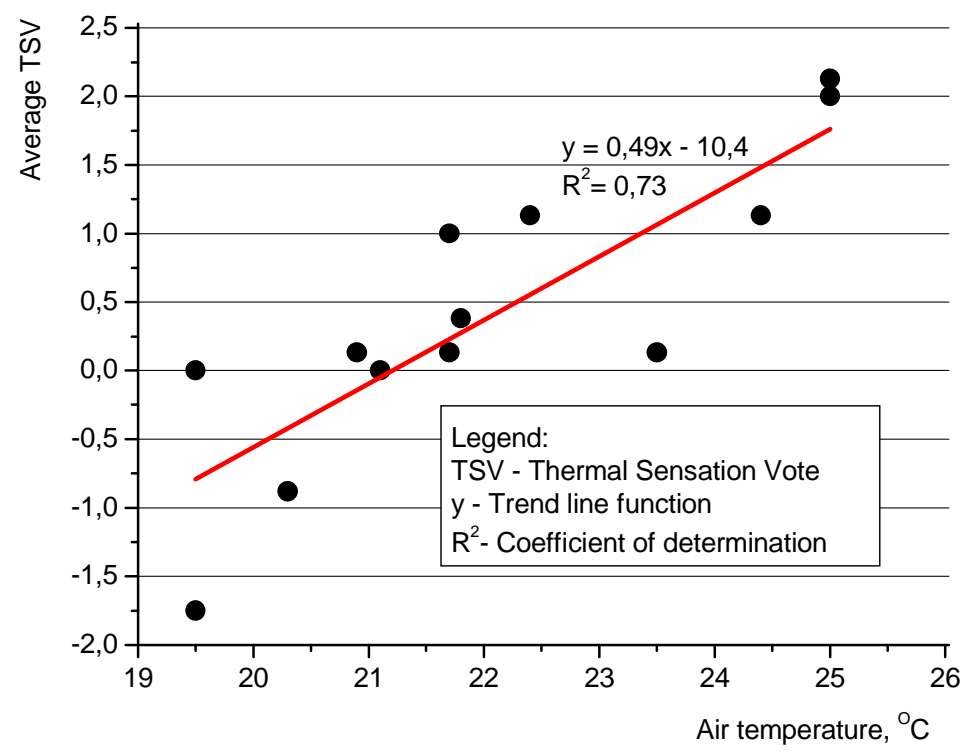

Fig. 7: Relationship between temperature and Thermal Sensations Vote (TSV).

The research carried out (Fig. 7) shows that temperature influences the thermal impressions felt by the respondents. During low temperatures, such as $19.5^{\circ} \mathrm{C}, 20.3^{\circ} \mathrm{C}$, the participants felt cooled down, so they did not feel comfortable in the room. However, the graph above shows that the respondents also felt comfortable at $19.5^{\circ} \mathrm{C}$. This discrepancy may be due to the clothing of the respondents during the survey. In the case of temperatures of $24.4{ }^{\circ} \mathrm{C}$ and $25{ }^{\circ} \mathrm{C}$, their thermal impressions were opposite. The respondents were satisfied with the environment in which they stayed when the value of the air temperature in the room ranged from $20.9^{\circ} \mathrm{C}$ to $23.5^{\circ} \mathrm{C}$. Summing up, the conducted research has shown that when the temperature in the room is too high or too low, a person does not feel comfortable and experiences thermal discomfort.

The above graph (Fig. 7) shows that in 6 cases only the average TSV was between +0.5 and -0.5 in 14 tests at different temperatures and humidity. This means that in most cases the respondents did not feel comfortable in the room they were in, because in 8 out of 14 tests the average TSV was between -0.88 and 2.13. The diagram below (Fig. 8) shows the relationship between the temperature in the room and the thermal preferences vote (TPV) of the respondents.

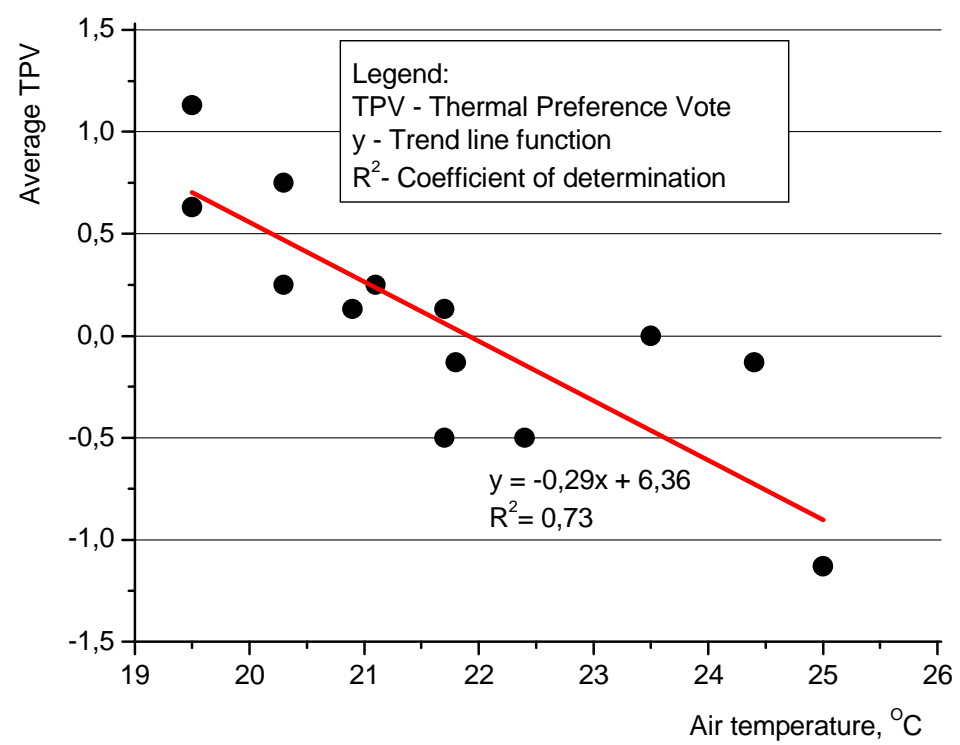

Fig. 8: Relationship between temperature and Thermal Preferences Vote (TPV).

In the graph above (Fig. 8), it can be seen that respondents with air temperatures ranging from $19.5^{\circ} \mathrm{C}$ to $21.7^{\circ} \mathrm{C}$ did not feel comfortable and would like the temperature to be higher. Above these values, the participants assessed their preferences as indifferent or thought that the room should be cooler. The conducted research shows that the higher the temperature in the room, the more people 
expect the temperature to drop in order to feel thermal comfort. In the event of a too low temperature, the opposite is true. Below is a diagram (Fig. 9) of the relationship between humidity and thermal sensation vote of the respondents.

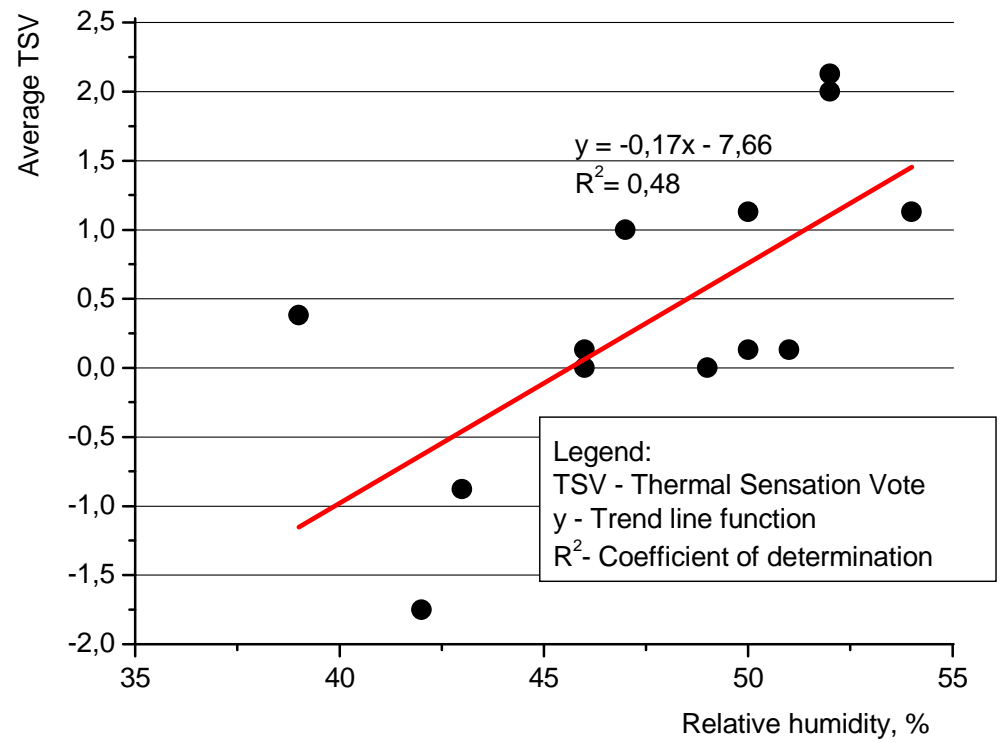

Fig. 9: The relationship between humidity and Thermal Sensations Vote (TSV).

The research shows that humidity influences the thermal impression felt by humans. In the above graph (Fig. 9) it can be seen that the higher the value of humidity, the more thermal impressions are in the direction 'too warm'. This means that if the room is too humid, the person does not feel comfortable.

\section{Comparison of test results with the Fanger model}

From the obtained results a graph was drawn up comparing the average TSV with the PMV index, which was estimated according to the Fanger model based on [15]. The metabolic rate for a seated person of 1 meter and thermal insulation of clothing of 0.57 clo were used for calculations. The comparison of the study results with the Fanger model is shown in Fig. 10.

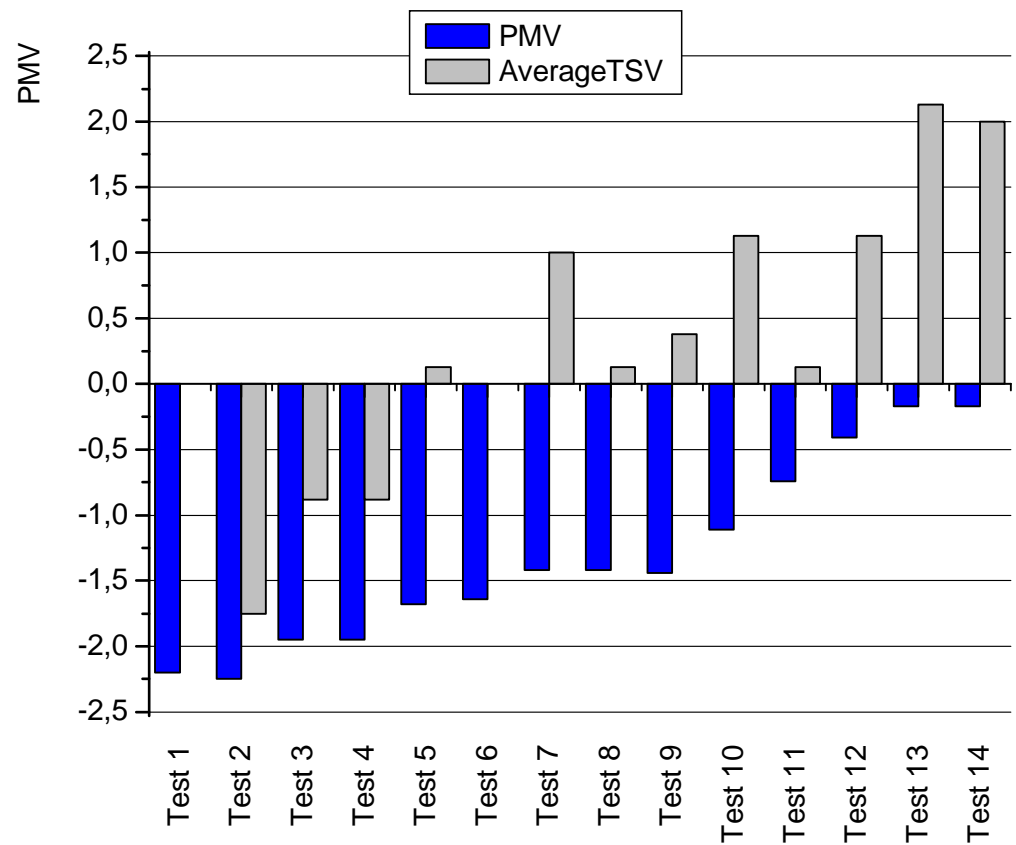

Fig. 10: Comparison of actual test results ('average TSV') with the Fanger model ('PMV'). 
It can be seen that Fanger's model does not correspond to the thermal impressions felt by humans in reality. There is only one case where the difference between PMV and average TSV is close to each other and is 0.5 . This is a test carried out at $19.5^{\circ} \mathrm{C}$ with a relative humidity of $42 \%$. In other cases, the difference between the estimated Fanger model and the actual thermal experience is between 0.87 and 2.42. Such a difference may be due to the estimation and not the calculation of PMV due to the impossibility to determine the radiation temperature or air speed. The second reason may be the influence of other factors on human thermal comfort, which is not taken into account in the Fanger model.

\section{Conclusions}

The research on thermal sensations shows that the respondents did not feel good in the considered room - the percentage of responses $+3,+2,-2,-3$ exceeded $10 \%$ and amounted to $25 \%$. Moreover, the second evidence of this is the average thermal sensation vote (TSV), because as many as 8 studies out of 14 indicated an average TSV above +0.5 and below -0.5 . However, it can be concluded from the studies that men were more satisfied with the conditions in the room than women. In the case of the temperature felt by the respondents, men also felt a $7.14 \%$ more acceptable temperature in relation to women.

However, regarding thermal preferences, the respondents gave very similar answers. In most cases, they thought that the temperature in the room is fine and should not be changed. The general thermal sensations of the respondents indicated that they felt good in their environment.

Comparing the temperature in the room and the thermal sensations and preferences, it can be seen that the temperature affects the thermal sensations of a person. As the temperature increases, a person feels badly in a room because it is too hot and a person wants it to be cooler and the other way around. The situation is similar with humidity. The higher the humidity, the person feels that the room is too hot. Dissatisfaction with the conditions in the room may result from the lack of air conditioning, which would allow improving these conditions.

From the comparison of the actual TSV thermal sensations with the PMV coefficient based on the Fanger model, it can be concluded that the thermal sensations are inconsistent with the adopted model contained in the standard. This may be due to other factors that were not included in the Fanger model. There is no doubt that further research should be carried out and other factors taken into account. The current research has mainly focused on thermal sensation in a single-family building. In future studies, the results of respondents could be compared with the Fanger model together with other factors.

\section{References}

[1] FANGER, P. O.: Komfort cieplny. Arkady, 1974.

[2] PN-EN ISO 7730: 2006 Ergonomics of the thermal environment - Analytical determination and interpretation of thermal comfort using calculation of the PMV and PPD indices and local thermal Comfort criteria.

[3] ASHRAE STANDARD 55 - 2004: Thermal Environmental Conditions for Human Occupancy.

[4] PN-EN 16798-1:2019, Energy Performance of Buildings-Ventilation for Buildings-Part 1: Indoor Environmental Input Parameters for Design and Assessment of Energy Performance of Buildings Addressing Indoor Air Quality, Thermal Environment, Lighting and Acoustics.

[5] KIIL, M. - SIMSON, R. - THALFELDT, M. - KURNITSKI, J.: A Comparative Study on Cooling Period Thermal Comfort Assessment in Modern Open Office Landscape in Estonia. Atmosphere, 11, 127, 2020.

[6] MAJEWSKI, G. - TELEJKO, M. - ORMAN, Ł. J.: Analysis of thermal comfort in an intelligent building. Civil and Environmental Engineering, 13 (1), 2017, pp. $72-76$.

[7] MAJEWSKI, G. - TELEJKO, M. - ORMAN, Ł. J.: Preliminary results of thermal comfort analysis in selected buildings. Proc. of Conf. on Interdisciplinatry Problems in Environmental Protection and Engineering (EKO-DOK), Poland, E3S Web of Conferences, 17, 00056, 2017.

[8] SIEW, C. C. - CHE-ANI, A. I. - TAWIL, N. M. - GOH-ABDULLAH, N. A. - UTABERTA, N.: Effectiveness of Thermal Comfort Models to Evaluate Occupants' Satisfaction Levels in Office Buildings. Building and Environment (20), 2011, pp. 372-379.

[9] RICCIARDI, P. - BURATTI, C.: Environmental quality of university classrooms: Subjective and objective evaluation of the thermal, acoustic, and lighting comfort conditions. Building and Environment, 127, 2018,.pp. 23-36. 
[10] JAZIZADEH, F. - MARIN, F. M. - BECERIK-GERBER, B.: A thermal preference scale for personalized comfort profile identification via participatory sensing. Building and Environment, 68, 2013, pp. 1440-149.

[11] JI, W. - CAO, B. - LUO, M. - ZHU, Y.: Influence of short-term thermal experience on thermal comfort evaluations: A climate chamber experiment. Building and Environment, 114, 2017, pp. 246-256.

[12] HOMODA, R. Z. - SAHARIA, K. S. H. - ALMURIB, H. A. F. - NAGI, F. H.: RLF and TS fuzzy model identification of indoor thermal comfort based on PMV/PPD. Building and Environment, 49, 2012, pp. 141-153.

[13] PIOTROWSKI, J. ZB. - ORMAN, Ł. J. - LUCAS, X. - ZENDER - ŚWIERCZ, E. - TELEJKO, M. KORUBA, D.: Tests of thermal resistance of simulated walls with the reflective insulation. Proc. of Int. Conf. Experimental Fluid Mechanics 2013, Czech Republic, EPJ Web of Conferences, 67, 02095, 2014.

[14] MAJEWSKI, G. - ORMAN, Ł. J. - TELEJKO, M. - RADEK, N. - PIETRASZEK, J. - DUDEK, A.: Assessment of thermal comfort in the intelligent buildings in view of providing high quality indoor environment. Energies, 13(8), 1973, 2020.

[15] https://comfort.cbe.berkeley.edu/EN. 